\title{
5-a-day fruit and vegetable food product labels: reduced fruit and vegetable consumption following an exaggerated compared to a modest label
}

\author{
K. M. Appleton ${ }^{1,2^{*}}$ (ID and H. J. Pidgeon ${ }^{1}$
}

\begin{abstract}
Background: Food product labels based on the WHO 5-a-day fruit and vegetable (FV) message are becoming increasingly common, but these labels may impact negatively on complementary or subsequent FV consumption. This study aimed to investigate the impact of a '3 of your 5-a-day' versus a '1 of your 5-a-day' smoothie product label on subsequent FV consumption.

Methods: Using an acute experimental design, 194 participants (90 males, 104 females) were randomised to consume a smoothie labelled as either ' 3 of your 5 -a-day' $(N=97)$ or ' 1 of your 5 -a-day' $(N=97)$ in full, following a usual breakfast. Subsequent FV consumption was measured for the rest of the day using 24-h recall. Usual FV consumption was also assessed via 24-h recall for the day before the study.

Results: Regression analyses revealed a significantly lower subsequent FV consumption following smoothies displaying the ' 3 of your 5 -a-day' label compared to the ' 1 of your 5 -a-day' label (Beta $=-0.15, p=0.04$ ). Secondary analyses revealed these effects to be driven mainly by changes to consumption in usual high FV consumers, in females and in vegetable as opposed to fruit consumption.

Conclusions: These findings demonstrate a role for label information in food intake, and the potential negative impacts of an exaggerated food product label on healthy food consumption and healthy dietary profiles.
\end{abstract}

Keywords: Fruit and vegetables, 5-a-day, Labels, Intake

\section{Background}

There is a current trend for food manufacturers' to add labels to food products to promote their contributions to health. One example of this is the addition of labels to fruit and vegetable (FV) food products based on contribution to World Health Organization and/or Government guidelines for health [1-3]. For example, in relation to the 5-a-day message in the UK [3], labels featuring '... of your 5-a-day' are found on FV food products, and similar labels are found in other countries, based on local recommendations.

\footnotetext{
* Correspondence: k.appleton@bournemouth.ac.uk

${ }^{1}$ Research Centre for Behaviour Change, Department of Psychology, Bournemouth University, Bournemouth BH12 5BB, UK

${ }^{2}$ Research Centre for Behaviour Change, Department of Psychology, Bournemouth University, Poole House, Fern Barrow, Poole BH12 5BB, UK
}

Evidence suggests that healthy food product labels can result in improved food product selection and purchasing [4-6]. More low-calorie and low-fat products, and less high-calorie and high-fat products were purchased in a canteen following the introduction of 'high-' and 'low-' 'calorie' and 'fat' labels for products [4], and more products labelled 'healthy' and less products labelled 'unhealthy' were purchased in a cafeteria setting over 3 months [5], and over one and two years [6].

This improved selection and purchasing can result in improved consumption at least to some degree $[5,6]$. Limited evidence however, also suggests that healthy food product labels can result in reduced heathy food consumption. Participants consumed more cookies that were labelled 'healthy' than cookies that were labelled 'gourmet' in a laboratory taste test [7]. Consumers in an

(c) The Author(s). 2018 Open Access This article is distributed under the terms of the Creative Commons Attribution 4.0 International License (http://creativecommons.org/licenses/by/4.0/), which permits unrestricted use, distribution, and reproduction in any medium, provided you give appropriate credit to the original author(s) and the source, provide a link to the Creative Commons license, and indicate if changes were made. The Creative Commons Public Domain Dedication waiver (http://creativecommons.org/publicdomain/zero/1.0/) applies to the data made available in this article, unless otherwise stated. 
open buffet setting consumed more M\&Ms labelled 'low fat' as opposed to 'regular' [8]. Consumers given a free 'healthy' food product in a fast food restaurant ordered more regular drinks and cookies, than consumers given a free 'unhealthy' food product [9]. Participants consumed more for lunch after a 'low fat' yoghurt preload than after a 'high fat' yoghurt preload in the laboratory [10], and participants consumed more for the total day after a 'low fat' lunch compared to a 'high fat' lunch [11]. These increased intakes are thought to result from a form of licencing, where adherence to a longer-term goal allows transgressions or indulgences that counter that longer-term goal $[8,9,12-14]$. Thus adhering to a lowfat diet through the consumption of low-fat products may allow greater consumption of those products compared to regular products, greater consumption of complementary non-low-fat products, or greater subsequent consumption in general.

Furthermore, where goals are specific and progress can be monitored, e.g. in the consumption of 5 portions of FV per day, early adherence to a goal can reduce later effort and subsequent later performance leading to a tendency to meet a goal rather than exceed it [15-17]. Thus, a food product label featuring a ' 2 of your 5-a-day' message will likely result in the subsequent consumption of only up to three more FV portions that day as opposed to more than this, despite the scientific evidence reporting increasing health benefits with increasing FV consumption [18].

Thus, food product labels that highlight the healthy component of a product can have positive impacts of healthy dietary profiles, but licencing and goal adherence may reduce or negate these positive impacts. This situation is further worsened if the 'healthy component' portrayed in a food product label is exaggerated. The WHO 5-a-day FV guidelines generally recommend consideration of fruit juice as only one FV portion regardless of quantity, for reasons based on processing and fibre breakdown [1-3]. Published work from Australia, however, suggests exaggeration of FV portion contribution by some FV juice and FV drink product labels [19]. In the UK, the National Health Service currently recommends 'Unsweetened 100\% fruit juice, vegetable juice and smoothies can only ever count as a maximum of one portion of your 5 A Day' [3], and the British Dietetic Association states 'A $150 \mathrm{ml}$ smoothie counts as one portion but some smoothies on the market today may contain two portions if they contain at least $150 \mathrm{ml}$ of fruit juice and at least $80 \mathrm{~g}$ of crushed fruit or vegetable pulp' [20], but many smoothies in the UK are labelled ' 2 of your 5a-day', without any inclusion of 'crushed fruit' in the ingredient list. Some recipes for home-made smoothies can also result in perceptions of 5-a-day contributions that are higher than the official one or two portions [21].
Exaggerated claims of the presence or proportion of FV provided by other food products were also found in the Australian study [19]. Few consumers furthermore may have the knowledge or inclination to look beyond a 5-aday label claim. Few consumers report knowing or understanding the specifics of the various 5-a-day messages [21-23], and the different rules for single food products have been reported as particularly difficult $[21,23]$.

Whether through licencing or goal adherence, this study aimed to investigate the impact on subsequent FV consumption of a ' 3 of your 5-a-day' versus a ' 1 of your 5-a-day' FV product label. We hypothesised that the ' 3 of your 5-a-day' label would result in a lower subsequent FV consumption compared to the ' 1 of your 5a-day' label.

\section{Methods}

Using an independent groups design, participants received a smoothie labelled either ' 3 of your 5 -a-day' or '1 of your 5-a-day' following a usual breakfast, and FV consumption for the rest of the day was measured.

\section{Participants}

In total, 194 participants (90 male, 104 female, aged 18 years and over) took part. Participants were recruited from the staff and student population of Bournemouth University, UK and surrounding area, and the study ran between February and April 2016. All individuals who volunteered for the study were invited to take part, unless individuals stated known food allergies. Sample size was based on other recent studies using similar messageand label-based interventions [8, 9, 24], and the use of a wide sample aimed to increase the ecological validity of the study. The study was advertised as a study investigating 'smoothie consumption in the morning', with an interest in how this might affect intake for the rest of the day. No reference was made to the product labels.

\section{Food product labels}

Two FV product labels were used. Each product label stated the product as a 'smoothie', included the smoothie flavour, and stated either ' 3 of your 5-a-day' or ' 1 of your 5-a-day', using the recognised national UK logo for the 5 -a-day FV message. ' 3 of your 5-a-day' or ' 1 of your 5-a-day' labels were chosen as an exaggerated and a modest label respectively, and considering that most smoothies in the UK are marketed as ' 2 of your 5-a-day' both labels would be perceived as equally incorrect. We did not include a ' 2 of your 5 -a-day' label to avoid confounding effects of the message with effects as a result of perceived accuracy / inaccuracy. Message labels were identical excepting the number of portions. No other information about the smoothies was provided on the smoothie labels. Ingredient and allergen information 
were provided and checked prior to inclusion in the study as part of the informed consent procedure. Labels were randomly allocated to participants by the participant drawing lots (equal chance of ether label), once each participant had provided consent and completed all initial measures. Three different smoothie flavours were used over the course of the study (Tesco 'Blueberry' Smoothie, Tesco 'Mango and Passionfruit' Smoothie, Tesco 'Strawberry and Banana' Smoothie, Cheshunt, UK), all currently marketed as ' 2 of your 5-a-day'. Each smoothie was provided in a refrigerated $250 \mathrm{ml}$ bottle, and all participants had a choice of one of two flavours.

\section{Subsequent FV consumption}

Subsequent FV consumption was assessed using 24-h recalls. The day after smoothie consumption, participants were asked to recall all foods consumed the previous day, using household portion sizes. The 24-h recall method was used as an accurate measure of food intake over a single day, and a measure of food intake reported as reliable for measuring FV intakes $[25,26]$. Food recalls were conducted by the researcher and checked at the time of completion for completeness and accuracy, using prompts for frequently missed food items, such as snacks, condiments, and drinks with meals [25, 26]. Food recalls were subsequently coded by the researcher for portions of fruit and portions of vegetables consumed based on current UK portion size guidelines [3]. All researchers who administered food recalls were trained in food recall methodology prior to the study and were familiar with current UK FV portions size guidelines [3].

Subsequent FV consumption was highly likely to be influenced by usual FV consumption [24, 27-29]. Usual FV consumption was assessed again using a 24-h recall completed for the day before smoothie consumption. This recall was completed on study entry, prior to smoothie consumption, and also served to familiarise participants with the 24-h recall procedure.

\section{Procedure}

The study was conducted in the Eating Behaviours Laboratory at Bournemouth University, Bournemouth, UK, in February-April, 2016. Participants were asked to attend the Laboratory between 8 am-11 am, following their usual breakfast, on two consecutive study days. On the first study day, participants first completed the 24-h recall as a measure of usual consumption, and secondly, were provided with and asked to consume a labelled smoothie of their choice. All participants were asked to look at their smoothie before consumption and were required to consume their smoothie in full, although neither the label nor the message were mentioned. Attention was not specifically drawn to the label or the 5- a-day message to more closely represent a real-world consumption scenario and increase the ecological validity of the study. Participants were also unaware of the alternate condition and label in the study. While participants, thus, were not blinded to study condition, biases in reporting were unlikely to be systematic between conditions. On the following day, participants were asked to return to the Laboratory at the same time, again completed the 24-h food recall, and were debriefed. The study took $20-30 \mathrm{~min}$ on each day to complete.

\section{Analyses}

All participants completed the study, and there were no missing data. Analyses were conducted on an Intentionto-Treat basis. Data were analysed by multiple linear regression, where subsequent FV consumption was firstly predicted by label type (model 1), and secondly also by usual FV consumption and gender (model 2). The second analyses were conducted to investigate the relative impact of the label compared to usual consumption. Gender was included following reports that both usual FV consumption and the impacts of food labels are typically higher in females compared to males [30-33]. Analyses were also conducted to explore whether usual high or low consumers and whether males or females were differentially affected by the labels [30-33]. These analyses investigated the impact of interactions between usual FV consumption and label type (FV consumption * label) (model 3) and gender and label type (gender * label) (model 4). In these regression models, subsequent FV consumption was predicted using the interaction term and the remaining predictor (gender and usual FV consumption respectively). Significant interaction terms would demonstrate that usual high or low consumers and/or that males or females were differentially affected by the labels taking other variables into account. Analyses were conducted for FV consumption, and for fruit consumption and vegetable consumption separately [34].

\section{Results}

In total, 97 participants received a smoothie with the ' 3 of your 5-a-day' label (46 males, 51 females), and 97 participants received a smoothie with the ' 1 of your 5 -aday' label (44 males, 53 females). No other demographic details for participants were collected.

\section{FV consumption}

Mean (sd.) subsequent FV consumption for the ' 3 of your 5-a-day' group was 1.8 (1.6) FV portions, and for the ' 1 of your 5-a-day' group was 2.3 (2.0) FV portions. A split of the numbers of participants consuming 0, 0.5$1,1.5-2,2.5-3,3.5-4,4.5-5$ and 5.5 plus FV portions subsequently in each group is given in Table 1 . Daily FV 
Table 1 Number of participants consuming $0-5.5+$ subsequent $\mathrm{FV}$ portions in response to the '1 of you 5-a-day' label and the '3 of your 5-a-day' label $(N=194)$

\begin{tabular}{llllllll}
\hline Subsequent FV portions & 0 & $0.5-1$ & $1.5-2$ & $2.5-3$ & $3.5-4$ & $4.5-5$ & $5.5+$ \\
\hline 1 of your 5-a-day $(N=97)$ & 15 & 25 & 21 & 11 & 11 & 8 & 6 \\
3 of your 5-a-day $(N=97)$ & 21 & 29 & 20 & 12 & 10 & 3 & 2 \\
\hline
\end{tabular}

consumption was significantly lower in consumers who received the ' 3 of your 5 -a-day' label compared to those who received the ' 1 of your 5 -a-day' label $(R=0.15$, $\mathrm{R}^{2}=0.02$, adj. $\mathrm{R}^{2}=0.02, \mathrm{~F}(1,193)=4.42, p=0.04$; Beta $=$ $-0.15, p=0.04$ ).

On consideration also of usual consumption and gender, the regression model remained significant $(R=0.63$, $\mathrm{R}^{2}=0.40$, adj. $\left.\mathrm{R}^{2}=0.39, \mathrm{~F}(3,193)=42.03, p<0.01\right)$, but label type was no longer a significant predictor (Beta $=-$ $0.01, p=0.09$ ). Higher subsequent FV consumption was instead associated with higher usual FV consumption $($ Beta $=0.56, p<0.01)$, and being female $($ Beta $=-0.18$, $p<0.01)$.

Consideration of the interaction terms revealed greater effects of the labels in those of higher usual FV consumption (Beta $=0.34, p<0.01$ ), and in females (Beta = $-0.17, p<0.01$ ). Mean (sd.) subsequent and usual FV consumption in high and low FV consumers and in male and female consumers in response to the ' 3 of your 5 -aday' label and the ' 1 of your 5 -a-day' label are given in Tables 2 and 3 respectively.

\section{Fruit consumption}

No effects of label type were found on fruit consumption (Primary model: $R=0.10, \mathrm{R}^{2}=0.01$, adj. $\mathrm{R}^{2}=0.01$, $\mathrm{F}(1,193)=1.78, p=0.18$; Beta $=-0.10, p=0.18$; Secondary model: $R=0.52, \mathrm{R}^{2}=0.27$, adj. $\mathrm{R}^{2}=0.26, \mathrm{~F}(3,193)=23.68$, $p<0.01$; Beta $=-0.06, p=0.38$ ). Effects of usual fruit consumption and gender were found, as above (smallest Beta $=-0.19, p<0.01)$. Interactions between label type and usual fruit consumption and gender were also found, as above (smallest Beta $=-0.14, p=0.03$ ).

Table 2 Mean (sd.) (unadjusted) subsequent and usual FV consumption in high and low FV consumers in response to the '1 of you 5-a-day' label and the '3 of your 5-a-day' label $(N=194)$

\begin{tabular}{llll}
\hline & Label type & $\begin{array}{l}\text { Usual FV } \\
\text { consumption }\end{array}$ & $\begin{array}{l}\text { Subsequent FV } \\
\text { consumption }\end{array}$ \\
\hline $\begin{array}{l}\text { Low usual FV } \\
\text { consumers }\end{array}$ & $\begin{array}{l}1 \text { of your 5-a-day } \\
(N=60)\end{array}$ & $1.0(0.8)$ & $1.5(1.5)$ \\
& $\begin{array}{l}3 \text { of your 5-a-day } \\
(N=63)\end{array}$ & $0.9(0.8)$ & $1.3(1.5)$ \\
$\begin{array}{l}1 \text { of your 5-a-day } \\
\text { consumers }\end{array}$ & $4.4(1.5)$ & $3.7(1.9)$ \\
& $\begin{array}{l}3 \text { of your 5-a-day } \\
(N=34)\end{array}$ & $4.0(1.1)$ & $2.6(1.5)$ \\
\hline
\end{tabular}

Table 3 Mean (sd.) (unadjusted) subsequent and usual FV consumption in male and female consumers in response to the '1 of you 5-a-day' label and the ' 3 of your 5 -a-day' label $(N=194)$

\begin{tabular}{llll}
\hline & Label type & $\begin{array}{l}\text { Usual FV } \\
\text { consumption }\end{array}$ & $\begin{array}{l}\text { Subsequent FV } \\
\text { consumption }\end{array}$ \\
\hline Females & 1 of your 5-a-day $(N=53)$ & $2.5(2.1)$ & $2.7(2.3)$ \\
& 3 of your 5 -a-day $(N=51)$ & $2.4(1.9)$ & $2.3(1.8)$ \\
Males & 1 of your 5 -a-day $(N=44)$ & $2.0(1.9)$ & $1.8(1.4)$ \\
& 3 of your 5-a-day $(N=46)$ & $1.5(1.5)$ & $1.2(1.1)$ \\
\hline
\end{tabular}

\section{Vegetable consumption}

Vegetable consumption was significantly lower following the ' 3 of your 5 -a-day' label compared to the ' 1 of your 5-a-day' label $\left(R=0.19, R^{2}=0.04\right.$, adj. $R^{2}=0.03$, $\mathrm{F}(1,193)=6.95, p=0.01$; Beta $=-0.19, p=0.01)$. On consideration also of usual consumption and gender, the model remained significant $\left(R=0.61, R^{2}=0.38\right.$, adj. $\left.\mathrm{R}^{2}=0.37, \mathrm{~F}(3,193)=38.36, p<0.01\right)$, but the effects of label type were again reduced (Beta $=-0.16, p=0.02$ ), and higher subsequent vegetable consumption was also associated with higher usual vegetable consumption (Beta $=0.53, p<0.01)$, and being female (Beta $=-0.16$, $p=0.01$ ). On consideration of the interaction terms, greater effects of the labels were again found in those of higher usual vegetable consumption (Beta $=0.34$, $p<0.01$ ), and in females (Beta $=-0.21, p<0.01$ ).

Results of all regression analyses are provided in Table 4.

\section{Discussion}

Several key findings emerge from this study. Firstly, exposure to a ' 3 of your 5-a-day' FV label following a usual breakfast resulted in reduced subsequent FV consumption compared to exposure to a ' 1 of your 5 -aday' label. These findings mirror early findings where healthy food labels were found to result in reduced subsequent healthy food consumption $[10,11]$. These effects are most plausibly explained either as a licencing effect $[8,9,12-14]$, where consumers allow themselves lower adherence to a dietary goal (consuming $5 \mathrm{FV}$ a day) for the rest of the day as a result of their perceived earlier adherence to that goal, or as a goal adherence effect [15-17], where consumers consume healthy foods to a healthy food goal and no further, or as both. We cannot disentangle these two mechanisms in this study. We suggest however, that our effects are predominantly due to licencing. Effects due to goal adherence would have resulted in consumers in the ' 3 of your 5 -a-day' group consuming $2 \mathrm{FV}$ portions following the smoothie. However, 19 consumers in the ' 3 of your 5-a-day' group consumed $2 \mathrm{FV}$ portions following the smoothie, and this was no higher than the number that would have occurred by chance assuming equal distribution over $0-5$ FV portions $(n=16)$, than the number of consumers 


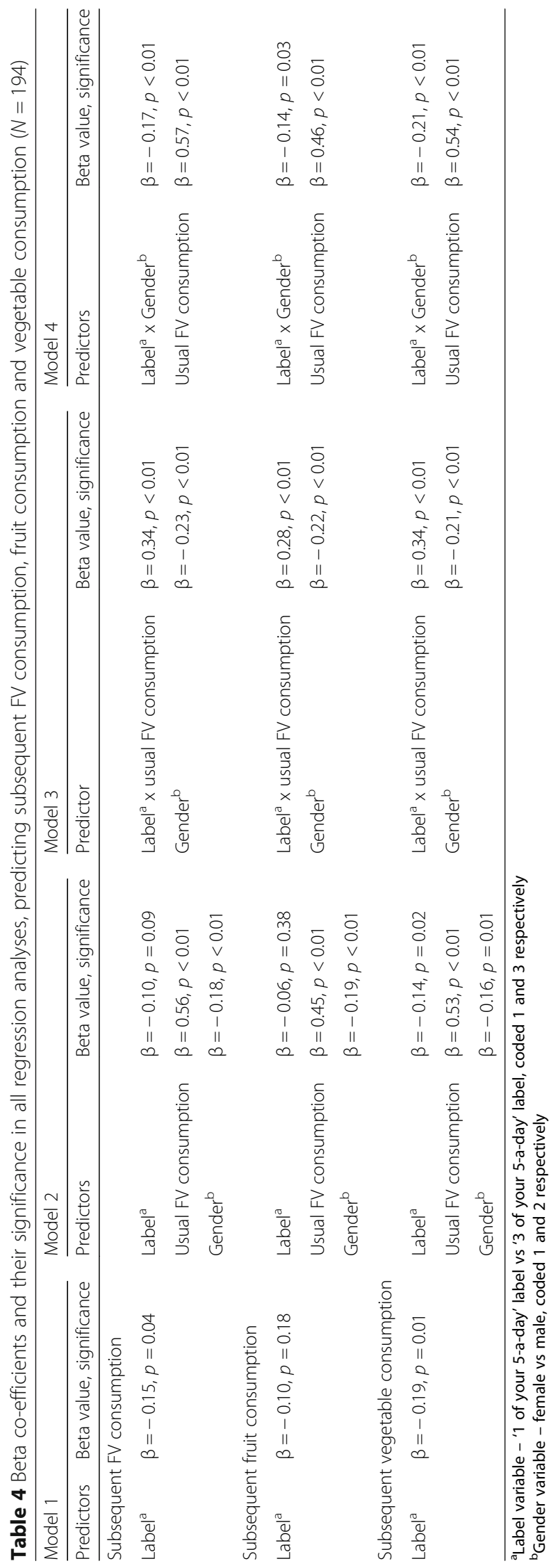


that usually consumed $2 \mathrm{FV}$ portions / day based on intake measures of the previous day $(n=15)$, or than the number of consumers consuming $2 \mathrm{FV}$ portions in the ' 1 of your 5 -a-day' group $(n=20)$ (largest $\chi^{2}=1.1, \mathrm{df}=1$, $p>0.05)$. An element of goal adherence may still have occurred to some degree, or in some individuals, and further investigation of mechanisms would clearly be of interest.

In a practical sense, these findings demonstrate a danger of providing information suggesting exaggerated FV provision on food product labels. FV consumption is known to be lower than WHO recommendations in Europe and the US [35, 36], and the levels of usual FV consumption reported in this study (mean $(\mathrm{sd}$.) $=2.1(1.9)$ portions of FV / day) are comparable with these reports $[35,36]$. The provision of a free smoothie resulted in an increase in mean consumption to 3.0 (1.8) FV portions on the following day, but individuals receiving a smoothie with the ' 3 of your 5 -a-day' label would have perceived their consumption at 5.0 (1.8) FV portions. Based on suggestions of goal-adherence, these consumers are unlikely to consume further FV on this day. Based on licencing, consumers may easily excuse themselves from consuming more. The detrimental impacts on FV consumption of the exaggerated message would suggest greater regulation may be required to ensure accuracy in these types of messages. Regulation is currently in place across Europe, the US and Australia on necessary food product information, such as the presence of allergens, and food product claims (e.g. [37-40]), but the specifics of these regulations can result in labels that misinform consumers [19]. We have no reason furthermore, to consider our findings to be specific to FV food product labels or UK consumers. Effects as a result of exaggerated claims may be more obvious for 5-a-day FV message labels, due to the use of a clear goal, and a goal that is well-known, but the same principles may be equally applicable to any dietary goal.

Secondly, these effects were reduced by consideration also of usual FV consumption and gender. These findings suggest firstly, that usual FV consumption and gender are more important predictors of subsequent FV consumption than the label provided, and secondly that the effects due to label are, at least partially, a result of some interaction between label, usual FV consumption and gender. The higher FV consumption in the study by usual high consumers and by females is unsurprising. Repeated previous research demonstrates the importance of habit or usual practices in FV consumption [24, 27-29], and the usual higher consumption of FV by females compared to males [30, 33].

The interaction effects reveal differential effects of the label dependent on usual FV consumption and gender. These findings are noteworthy. Different effects of food labels on different consumers has previously been suggested elsewhere [7, 9, 14, 41, 42]. In our study, greater effects of the label were found in usual high consumers of FV and in females. These findings may suggest that high consumers of FV and females consume high amounts of FV as a result of deliberate portion counting and other cognitive methods. Various work suggests a high cognitive input into healthy eating including FV consumption $[28,29,43-45]$, and that females are more inclined to use these cognitive methods than males $[46,47]$. Work on the cognitive controls of eating behaviour, and particularly work on dietary restraint, suggests that these cognitive methods can be effective, but can also be prone to disruption through environmental or emotional cues [10,11, 24, 46-49]. The findings of this study could demonstrate a clear disruption to cognitively controlled eating behaviour as a result of (mis) information.

Effects in FV consumption were also largely driven by effects in vegetable consumption not in fruit consumption. These effects are surprising given that the smoothies used in the study were predominantly fruit smoothies, but various evidence suggests that individuals tend to find it easier to consume fruit than vegetables $[34,50]$. Thus, while the 5 -a-day message relates to fruit and vegetables together, any additional $\mathrm{FV}$ consumption may have an impact on the more difficult (vegetable consumption) as opposed to the easier (fruit consumption) goal. These findings may also demonstrate a disadvantage of the combination of fruit and vegetables in the WHO 5-a-day message. Recognition of the health benefits and the low consumption of vegetables specifically has resulted in the use of separate messages for fruits and for vegetables by certain Governments [34].

Comparable to our effects on fruit consumption, other studies also demonstrate no effects on intake as a result of food product labels [41, 42, 51]. These studies suggest greater impacts on intake as a result of other properties of a food product, such as texture [51], or suggest an important role for individual differences [41, 42], including socio-demographic $[7,42]$ or personality characteristics $[9,14,42]$. Our study is limited by our lack of assessment of these other characteristics of potential influence, although randomisation procedures should have ensured that any bias was unsystematic. We also took no assessment of participant's perceptions of the smoothies. It is possible that the smoothie with a ' 3 of your 5-a-day' label was perceived to be larger or more energy dense than the alternate smoothie, and so may have resulted in a lower intake of all foods. However, given the assessment of food intake over a whole day, and a usual very limited compensation for small amounts of energy over a whole day [49], we consider this possibility unlikely.

Our study is also limited by the use of predominantly educated individuals, and it can be argued that food 
product labels may be of greater value in less educated individuals [52]. We also did not use a 'no label' control to investigate the effects of labels per se. Investigation of the effects of a label vs no label was not the purpose of this study. Other studies suggest that labels can improve dietary profiles compared to no labels [52, 53], although small and limited impacts in general have also been suggested [54].

Finally, as an unintended outcome, our study also demonstrates an impact of providing a free fruit smoothie on daily FV consumption. Mean total daily FV consumption increased from a mean (sd.) of 2.1 (1.9) portions of FV / day) on the day before consuming the smoothie (usual consumption) to a mean (sd.) daily consumption of 3.0 (1.8) FV portions when a smoothie was provided. Other studies demonstrate increased consumption as a result simply of increased provision [55-58], and this study confirms increased provision as a strategy for increasing FV consumption.

\section{Conclusions}

In conclusion, consumption of a smoothie sporting a ' 3 of your 5-a-day' food product label compared to a '1 of your 5-a-day' food product label resulted in reduced subsequent FV consumption, and this effect was largely driven by changes in consumption in usual high FV consumers, in females, and in vegetable as opposed to fruit consumption. Effects are likely driven by cognitive controls of food intake, such that perceived earlier adherence to a healthy dietary goal results in licenced transgressions or reduced efforts towards reaching that goal. The findings demonstrate a potential negative role for healthy food product labels in healthy dietary consumption.

\section{Acknowledgements}

Grateful thanks are extended to Mollie Leane and Sophie Padfield, Bournemouth University for help with data collection and inputting.

\section{Funding}

The study was supported by Bournemouth University, Bournemouth, UK.

\section{Availability of data and materials}

The dataset created and analysed for the current study is available from the corresponding author on reasonable request.

\section{Authors' contributions \\ KMA designed the research. HJP conducted the study. KMA undertook the analyses. Both authors wrote and revised the manuscript. Both authors read and approved the final version of the manuscript.}

\section{Ethics approval and consent to participate}

The study was approved by Bournemouth University Research Ethics Committee and conducted according to the guidelines laid down in the Declaration of Helsinki and by the British Psychology Society. Written informed consent was obtained from all participants prior to their involvement in the study.

\section{Competing interests}

The authors declare that they have no competing interests.

\section{Publisher's Note}

Springer Nature remains neutral with regard to jurisdictional claims in published maps and institutional affiliations.

Received: 24 July 2017 Accepted: 1 May 2018

Published online: 15 May 2018

\section{References}

1. World Health Organisation. Diet, nutrition and the prevention of chronic diseases. In: WHO technical report series, vol. 797. Geneva: WHO; 1990.

2. World Health Organisation. Diet, nutrition and the prevention of chronic diseases. Report of a joint FAO/WHO expert consultation. In: WHO technical report series, No. 916. Geneva: WHO; 2003.

3. National Health Service, UK. Website: http://www.nhs.uk/Livewell/5ADAY/ Pages/Portionsizes.aspx. Accessed 28 Jul 2016.

4. Cioffo CE, Levitsky DA, Pacanowski CR, Bertz F. A nudge in a healthy direction. The effect of nutrition labels on food purchasing behaviors in university dining facilities. Appetite. 2015;92:7-14.

5. Thorndike AN, Sonnenberg L, Riis J, et al. A 2-phase labeling and choice architecture intervention to improve healthy food and beverage choices. Am J Public Health. 2012;102:527-33.

6. Thorndike AN, Riis J, Sonnenberg LM, Levy DE. Traffic-light labels and choice architecture: promoting healthy food choices. Am J Prev Med. 2014;46:143-9.

7. Provencher V, Polivy J, Herman CP. Perceived healthiness of food. If it's healthy, you can eat more. Appetite. 2009;52:340-4.

8. Wansink B, Chandon P. Can low fat nutrition labels lead to obesity? J Cons Res. 2006;153:605-17.

9. Chandon P, Wansink B. The biasing health halos of fast-food restaurant health claims. Lower calorie estimates and higher side-dish consumption intentions. J Mark Res. 2007;34:301-14.

10. Shide DJ, Rolls BJ. Information about the fat content of preloads influences energy intake in healthy women. J Am Diet Assoc. 1995;95:993-8.

11. Caputo FA, Mattes RD. Human dietary responses to perceived manipulation of fat content in a midday meal. Int J Obes. 1993;17:237-40.

12. Dhar R, Simonson I. Making complimentary choices in consumption episodes: highlighting versus balancing. J MarkRes. 1999;36:29-44.

13. Fishbach A, Dhar R. Goals as excuses or guides: the liberating effect of perceived goal progress on choice. J Cons Res. 2005;32:370-7.

14. Ramanathan S, Williams P. Immediate and delayed emotional consequences of indulgence: the moderating influence of personality type on mixed emotions. J Cons Res. 2007:34:212-23.

15. Cullen KW, Baranowski T, Smith SP. Using goal setting as a strategy for dietary behavior change. J Am Diet Assoc. 2001;101:562-6.

16. Locke EA, Latham GP. Building a practically useful theory of goal setting and task motivation: a 35 year odyssey. Am Psychol. 2002;57:705-17.

17. Locke EA, Shaw KN, Saari LM, Latham GP. Goal setting and task performance: 1969-1980. Psychol Bull. 1981;1:125-52.

18. Oyebode O, Gordon-Dseagu V, Walker A, Mindell JS. Fruit and vegetable consumption and all-cause, cancer and CVD mortality: analysis of health survey for England data. J Epidemiol Community Health. 2014;68:856-62.

19. Wellard L, Hughes C, Tsang YW, et al. Investigating fruit and vegetable claims on Australian food packages. Pub. Health Nutr. 2015;18:2729-35.

20. British Dietetic Association, UK. Website: https://www.bda.uk.com/foodfacts/ FruitVeg.pdf. Accessed 04 Aug 2016.

21. Carter OBJ, Pollard CM. Atkins JFP, et al. 'We're not told why - we're just told': qualitative reflections about the western Australian go for $2 \& 5$ fruit and vegetable campaign. Pub Health Nutr. 2010;14:982-8.

22. Dixon $H$, Mullins R, Wakefield M, Hill D. Encouraging the consumption of FVs by older Australians: an experiential study. J Nutr Educ Behav. 2004;36: 245-9.

23. Rooney C, McKinley MC, Appleton KM, et al. How much is '5-a-day'?: A qualitative investigation into consumer understanding of fruit and vegetable intake guidelines. J Hum Nutr Diet. 2017;30:105-13.

24. Appleton KM. Greater fruit selection following an appearance-based compared to a health-based health promotion poster. J Public Health. 2016:38:731-8.

25. Eaton DK, O'Malley Olsen E, Brener ND, et al. A comparison of fruit and vegetable intake estimates from three survey question sets to estimates from 24-hour dietary recall interviews. J Acad Nutr Diet. 2013;113:1165-74.

26. Salvador Castell G, Serra-Majem L, Ribas-Barba L. What and how much do we eat? 24-hour dietary recall method. Nutr Hosp. 2015;31:46-8. 
27. Adams C, Rennie L, Uskul AK, Appleton KM. Visualising future behavior: effects for snacking on biscuit bars, but no effects for snacking on fruit. Health Psychol. 2015;20:1037-48.

28. De Bruijn G-J. Understanding college students' fruit consumption: integrating habit strength in the theory of planned behaviour. Appetite. 2010:54:16-22.

29. De Bruijn G-J, Kremers SPJ, de Vet E, et al. Does habit strength moderate the intention-behaviour relationship in the theory of planned behaviour? The case of fruit consumption. Psychol Health. 2007;22:899-916.

30. Henderson L, Gregory J, Swan G. The National Diet and nutrition survey: adults aged 19 to 64 years. Technical report. Social survey division of the Office for National Statistics. London: The Stationary Office; 2002.

31. Neuhouser ML, Kristal AR, Patterson RE. Use of food nutrition labels is associated with lower fat intake. J Am Diet Assoc. 1999;99:45-53.

32. Ollberding NJ, Wolf RL, Contento I. Food label use and its relation to dietary intake among US adults. J Am Diet Assoc. 2011;111:S47-51.

33. Prattala R, Paalanen L, Grinberga D, et al. Gender differences in the consumption of meat, fruit and vegetables are similar in Finland and the Baltic countries. Eur J Pub Health. 2007;5:520-5.

34. Appleton KM, Hemingway A, Saulais $L$, et al. Increasing vegetable intakes: rationale and systematic review of published interventions. Eur J Nutr. 2016;55:869-96

35. European Food Safety Authority. Concise Database summary statistics Total population. Available at: http://www.efsa.europa.eu/en/datexfoodcdb/ datexfooddb.htm. Accessed 10 Mar 2018.

36. United States Department of Agriculture. Available at: http://www.ers.usda.gov/ Data/FoodConsumption/FoodAvailSpreadsheets.htm. Accessed 10 Mar 2018.

37. EU Regulation $1169 / 2011$ on the provision of food information to consumers. Available at: www.eur-lex.europa.eu. Accessed 10 Mar 2018.

38. Food Standards Agency UK. The food labelling regulations 1996. Available at: www.food.gov.uk/sites/default/files/multimedia/pdfs/fguidnot1.pdf. Accessed 10 Mar 2018

39. Food Standards Australia New Zealand. Australia New Zealand Food Standards Code. Available at: http://www.foodstandards.gov.au/ foodstandards/foodstandardscode.cfm. Accessed 10 Mar 2018.

40. US Department of Health and Human Services. A food labelling guide. Available at: https://www.fda.gov/downloads/Food/GuidanceRegulation/ GuidanceDocumentsRegulatorylnformation/UCM265446.pdf Accessed 10 Mar 2018

41. Carbonneau E, Peron J, Drapeau V, et al. Impact of nutritional labelling on 10-d energy intake, appetite perceptions, and attitudes towards food. Brit. J Nutr. 2015;114:2138-47.

42. Crockett RA, Jebb SA, Hankins M, Marteau TM. The impact of nutritional labels and socioeconomic status on energy intake: an experimental field study. Appetite. 2014;81:12-9.

43. Ästrøm AN, Rise J. Young adults' intention to eat healthy food: extending the theory of planned behavior. Psychol Health. 2001;16:223-37.

44. Bogers RP, Brug J, van Assema P, Dagnelle PC. Explaining fruit and vegetable consumption: the theory of planned behavior and misconception of personal intake levels. Appetite. 2004;42:157-66.

45. Deshpande S, Basil MD, Basil DZ. Factors influencing healthy eating habits among college students: an application of the health belief model. Health Mark Quart. 2009;26:145-64.

46. Herman CP, Polivy J. Self-regulation and the obesity epidemic. Soc Issues Policy Rev. 2011;5:37-69.

47. Nguyen C, Polivy J. Eating behaviour, restraint status and BMI of individuals high and low in perceived self-regulatory success. Appetite. 2014;75:49-53.

48. Polivy J, Herman CP, Coelho JS. Caloric restriction in the presence of attractive food cues: external cues, eating and weight. Physiol Behav. 2008. 94:729-33.

49. Appleton KM, McKeown PP, Woodside JV. Energy compensation in the real world: good compensation for small portions of chocolate and biscuits over short time periods in complicit consumers using commercially available foods. Appetite. 2015;85:104-10.

50. Neville C, McKinley M, Draffin C, et al. Participating in a fruit and vegetable intervention trial improves longer term fruit and vegetable consumption and barriers to fruit and vegetable consumption: a follow-up of the ADIT study. Int J Behav Nutr Phys Act. 2015;12:158.

51. Chambers L, Ells H, Yeomans MR. Can the satiating power of a high energy beverage by improved by manipulating sensory characteristics and labe information? Food Qual Pref. 2013;28:271-8.
52. Ellison B, Lusk JL, Davis D. Looking at the label and beyond: the effects of calorie labels, health consciousness and demographics on caloric intake in restaurants. Int J Behav Nutr Phys Act. 2013;10:21.

53. Roberto $\mathrm{CA}$, Larsen $\mathrm{PD}$, Agnew $\mathrm{H}$, et al. Evaluating the impact of menu labelling on food choices and intake. Am J Public Health. 2010;100:312-8.

54. Harnack LJ, French SA. Effect of point-of-purchase calorie labelling on restaurant and cafeteria choices: a review of the literature. Int I Behav Nutr Phys Act. 2008;26:51.

55. Blatt AD, Roe LS, Rolls BJ. Hidden vegetables: an effective strategy to reduce energy intake and increase vegetable intake in adults. Am J Clin Nutr. 2011;93:756-63.

56. Gibson A, Edgar JD, Neville CE, et al. Effect of fruit and vegetable consumption on immune function in older people: a randomised controlled trial. Am J Clin Nutr. 2012;96:1429-36.

57. Rolls BJ, Roe LS, Meengs JS. Portion size can be used strategically to increase vegetable consumption in adults. Am J Clin Nutr. 2010;91:913-22.

58. Shenoy SF, Kazaks AG, Holt RR, et al. The use of a commercial vegetable juice as a practical means to increase vegetable intake: a randomized controlled trial. Nutr J. 2010;9:38.

\section{Ready to submit your research? Choose BMC and benefit from:}

- fast, convenient online submission

- thorough peer review by experienced researchers in your field

- rapid publication on acceptance

- support for research data, including large and complex data types

- gold Open Access which fosters wider collaboration and increased citations

- maximum visibility for your research: over $100 \mathrm{M}$ website views per year

At BMC, research is always in progress.

Learn more biomedcentral.com/submissions 